\title{
Commentary
}

\section{Comment on "Effect of transferred NK4 gene on proliferation, migration, invasion, and apoptosis of human prostate cancer DU145 cells" by Dan Yue et al. in Asian Journal of Andrology}

\author{
Shahriar Koochekpour \\ Stanley S. Scott Cancer Center, Departments of Microbiology and Immunology, Urology, and Biochemistry and Molecular \\ Biology, School of Medicine, Louisiana State University Health Sciences Center, New Orleans, LA 70112, USA
}

Fax: +1-504-568-6888 E-mail: skooch@1suhsc.edu Received: 31 March 2010 Accepted: 31 March $2010 \quad$ Published online: 19 April 2010

Asian Journal of Andrology (2010) 12: 444-446. doi: 10.1038/aja.2010.26; published online 19 April 2010.

Hepatocyte growth factor/scatter factor (HGF/SF) interacting with its cell surface receptor tyrosine kinase (RTK) c-met proto-oncogene drives downstream signaling pathways which lead to cell proliferation, migration, invasion, apoptotic cell-death protection, angiogenesis during embryogenesis, repair and regeneration, and neoplastic growth and metastatic progression [1-6].

In vitro and in vivo data support several mechanisms for c-met involvement in carcinogenesis including, but not limited to (1) c-met overexpression; (2) $\mathrm{HGF} / \mathrm{SF}$ overexpression; (3) establishment of HGF/ c-met autocrine loop; (4) activating mutations of c-met receptor; (5) establishment of $\mathrm{HGF} / \mathrm{c}-\mathrm{met}$ paracrine "stromal-epithelial" loop; and, (6) hypoxicinduction of HGF expression and/or c-met signaling leading to a dynamic interaction among tumor cells, mesenchymal cells, and acellular components of the tumor microenvironment [4, 7-10].

It is noteworthy that increased $\mathrm{HGF} / \mathrm{c}$-met expression and their autocrine and/or paracrine loop activation decreases thrombospondin 1 (a significant angiogenesis inhibitor) expression and upregulates the level of another potent angiogenic factor, vascular endothelial growth factor (VEGF) and one of its receptor isoforms, VEGRR2 [11]. Collectively, these events prove a potent angiogenic activity for c-met and $\operatorname{HGF}[12,13]$.

Overexpression and the contribution of c-met RTK and HGF have been documented for many solid and non-solid human malignancies such as lung, breast, genitourinary organs (kidney, bladder, prostate, ovary, cervix), the gastrointestinal system (gastric and colorectal), liver, head and neck, brain, skin, and the hematopoietic system [14-16].

Considering the profound contribution of $\mathrm{HGF} /$ c-met signaling and downstream pathway activation in carcinogenesis, tumor progression, and resistance to therapeutic modalities, it is not surprising that in the last few years, several biotechnology and pharmaceutical companies have actively participated in the design of selective or broad-spectrum HGF and /or c-met inhibitors and developed several phase I, II, III clinical trials $[17,18]$. These methods are aimed at preventing further tumor growth, decreasing tumor mass at metastatic sites, and preventing the formation of new metastatic foci or secondary metastases (i.e., metastasis of metastases). Essentially these strategies are based on the development of (1) humanized monoclonal antibodies against HGF or its cognate receptor, (2) biologically inactive competitive inhibitors of HGF, (3) competitive inhibitor of c-met, (4) synthetic small molecules functioning as selective kinase, multikinase, or broad-spectrum kinase inhibitor of c-met $[18,19]$.

HGF is a heterodimer of an $\alpha$-chain $(69 \mathrm{kDa})$ with 4 krinkle domains (K1-4) and an N-terminal hairpin loop linked to a $\beta$-chain $(34 \mathrm{kDa})$. The first two krinkle domains and the N-terminal loop are required for biological activity of HGF and their potential 
binding to the c-met receptor [2]. The natural NK1 and NK2 isoforms of HGF have been shown to have some agonistic activity and NK3 was found to have a growth promoting effect on endothelial cells [19]. NK4 is essentially the HGF without a $\beta$-chain. Since NK4 can bind to the c-met receptor but can not exert any biological activity, it functions as competitive inhibitor or antagonist for HGF[20]. NK4 has also been used by other investigators as a competitive HGF antagonist in prostate cancer cells [21,22]. Using in vitro and in vivo methodologies, recombinant NK4, recombinant $\mathrm{HGF}$, and conditioned medium of lung fibroblast (MRC5; known to express a large amount of HGF), Davies [21] et al. have demonstrated that NK4 decreases phosphorylative activity of c-met, migration, and invasion of an androgen-independent (AI) prostate cancer $(\mathrm{PCa})$ cells, $\mathrm{PC}-3$. In addition, by decreasing tumor-related angiogenesis, NK4 reduced PC-3 tumor growth in nude mice.

The paper by Yue et al. [23] "Effect of transferred NK4 gene on proliferation, migration, invasion, and apoptosis of human prostate cancer DU145 cells" provides independent proof of the role of NK4 as a complete HGF antagonist in another AI-PCa cell line, DU-145. By constructing a human NK4 cDNA expressing vector and establishing stable transfectants of NK4 in DU-145, Dr Yue and colleagues have shown that autocrine production of NK4 by DU-145/NK4 decreased HGF-induced cells proliferation, migration, invasion, and Akt- and ERK1-signaling pathways activation. In addition, the NK4 autocrine production increased the percentage of apoptotic cells in the presence of exogenously added HGF as demonstrated by TUNEL and FACS assays. Importantly, they have provided in vivo data validating their in vitro findings. Histological examination of DU-145/NK4 tumor tissues by TUNEL assay and an antibody against-PCNA showed that autocrine NK4 production decreased tumor growth by preventing paracrine HGF effects and increased apoptotic-cell death [23].

Due to the potent angiogenic effect of HGF, it would have been interesting to determine if the decrease in tumor growth was due to an inhibition of angiogenesis or was limited to cell proliferation. Histological examination of DU-145/NK4 xenograft with tumor endothelial markers could simply provide the answer. Since the majority of $\mathrm{PCa}$ metastasizes to the bone, the influence of NK4 autocrine on metastatic tumor formation in mice with a DU-145/NK4 xenograft could provide additional interesting data. Androgen-independent metastatic progression of $\mathrm{PCa}$ poses the most challenging problem in clinically managing the disease [24]. Future studies could be considered by using a co-culture of androgensensitive LNCaP transfectants expressing either NK4expression or empty vectors and MRC5 fibroblast or Matrigel matrix. As demonstrated by the pioneering work of Dr Leland Chung and his colleagues [25], combinations of tumor and mesenchymal cells or basement membrane proteins will allow a more realistic approach to evaluate the extent by which the autocrine NK4 production could affect tumor growth and metastasis or androgen-independent $\mathrm{PCa}$ progression in intact and castrated mice. Alternatively, orthotopic implantation of androgen-sensitive or AI-PCa cells (e.g., C4-2B) with or without the NK4 autocrine loop in the intact and castrated mice might provide data for NK4 effect on spontaneous metastases formation.

The fact that $\mathrm{PCa}$ is one of the most heterogeneous human tumors, might be a major reason for the failure of available strategies targeted at preventing HGF interaction with the c-met receptor and downstream post-receptor signaling pathways. In addition to the inherent heterogeneity of PCa, carcinogenesis could not be simplified by dysregulation of expression and/ or the function of a single gene (e.g., c-met or HGF) or signaling pathway. Knowing that the majority of metastatic PCa cells express cell surface prostate-specific membrane antigen (PSMA), targeted delivery of NK4mediated therapy to metastatic PCa cells can possibly provide a practical approach. There is a great need to develop individualized therapeutic interventions for cancer patients according to their unique molecular signatures for the disease. Dr Yue and his colleagues are to be commended for their current work and continuing their effort in a clinical translational setting for $\mathrm{PCa}$ therapy.

\section{References}

1 Nakamura T, Nishizawa T, Hagiya M, Seki T, Shimonishi $\mathrm{M}$, et al. Molecular cloning and expression of human hepatocyte growth factor. Nature 1989; 342: 440-3.

2 Nakamura T. Structure and function of hepatocyte growth factor. Prog Growth Factor Res 1991; 3: 67-85.

3 Bottaro DP, Rubin JS, Faletto DL, Chan AM, Kmiecik TE, et al. Identification of the hepatocyte growth factor receptor as the c-met proto-oncogene product. Science. 1991 Feb 15; 251: 802-4.

4 Vande Woude GF, Jeffers M, Cortner J, Alvord G, Tsarfaty I, et al. Met-HGF/SF: tumorigenesis, invasion and metastasis. 
Ciba Found Symp. 1997; 212: 119-30; discussion 130-2, 148-54.

5 Rosen EM, Goldberg ID. Scatter factor and angiogenesis. Adv Cancer Res 1995; 67: 257-79.

6 Birchmeier C, Gherardi E. Developmental roles of HGF/SF and its receptor, the c-Met tyrosine kinase. Trends Cell Biol. 1998; 8: 404-10.

7 Jeffers M, Koochekpour S, Fiscella M, Sathyanarayana BK, Vande Woude GF. Signaling requirements for oncogenic forms of the Met tyrosine kinase receptor. Oncogene. 1998 Nov 26; 17(21): 2691-700.

8 Jeffers M, Fiscella M, Webb CP, Anver M, Koochekpour $\mathrm{S}$, et al. The mutationally activated Met receptor mediates motility and metastasis. Proc Natl Acad Sci USA. 1998; 95: 14417-22.

9 Koochekpour S, Jeffers M, Rulong S, Taylor G, Klineberg $\mathrm{E}$, et al. Met and hepatocyte growth factor/scatter factor expression in human gliomas. Cancer Res. 1997; 57: 5391-8.

10 Jeffers M, Rong S, Anver M, Vande Woude GF. Autocrine hepatocyte growth factor/scatter factor-Met signaling induces transformation and the invasive/metastastic phenotype in C127 cells. Oncogene. 1996; 13: 853-6.

11 Xin X, Yang S, Ingle G, Zlot C, Rangell L, et al. Hepatocyte growth factor enhances vascular endothelial growth factorinduced angiogenesis in vitro and in vivo. Am J Pathol 2001; 158: 1111-20.

12 Zhang YW, Su Y, Volpert OV, Vande Woude GF. Hepatocyte growth factor/scatter factor mediates angiogenesis through positive VEGF and negative thrombospondin 1 regulation. Proc Natl Acad Sci USA 2003; 100: 12718-23.

13 You WK, McDonald DM. The hepatocyte growth factor/ c-Met signaling pathway as a therapeutic target to inhibit angiogenesis. BMB Rep. 2008; 41: 833-9.

14 Corso S, Migliore C, Ghiso E, De Rosa G, Comoglio PM, et al. Silencing the MET oncogene leads to regression of experimental tumors and metastases. Oncogene 2008; 27: 684-93.

15 Lesko E, Majka M. The biological role of HGF-MET axis in tumor growth and development of metastasis. Front Biosci. 2008; 13: 1271-80.

16 Benvenuti S, Comoglio PM. The MET receptor tyrosine kinase in invasion and metastasis. J Cell Physiol. 2007; 213: 316-25.

17 Eder JP, Vande Woude GF, Boerner SA, LoRusso PM. Novel therapeutic inhibitors of the c-Met signaling pathway in cancer. Clin Cancer Res. 2009; 15: 2207-14.

18 Cecchi F, Rabe DC, Bottaro DP. Targeting the HGF/Met signalling pathway in cancer. Eur J Cancer. 2010 Mar 18 [Epub ahead of print]

19 Silvagno F, Follenzi A, Arese M, Prat M, Giraudo E, et al. In vivo activation of met tyrosine kinase by heterodimeric hepatocyte growth factor molecule promotes angiogenesis. Arterioscler Thromb Vasc Biol. 1995; 15: 1857-65.

20 Nakamura T, Sakai K, Nakamura T, Matsumoto K. Anticancer approach with NK4: Bivalent action and mechanisms. Anticancer Agents Med Chem. 2010; 10: 36-46.

21 Davies G, Mason MD, Martin TA, Parr C, Watkins G, et al. The HGF/SF antagonist NK4 reverses fibroblast- and HGFinduced prostate tumor growth and angiogenesis in vivo. Int $\mathrm{J}$ Cancer. 2003; 106: 348-54.

22 Parr C, Davies G, Nakamura T, Matsumoto K, Mason MD, et al. The HGF/SF-induced phosphorylation of paxillin, matrix adhesion, and invasion of prostate cancer cells were suppressed by NK4, an HGF/SF variant. Biochem Biophys Res Commun. 2001; 285: 1330-7.

23 Dan Yue, Yong Wang, Ping Ma, Yin-Yan Li, Hong Chen, et al. Effect of transferred NK4 gene on proliferation, migration, invasion, and apoptosis of human prostate cancer DU145 cells. Asian J Androl 2010; 12: 381-389.

24 Feldman BJ, Feldman D. The development of androgenindependent prostate cancer. Nat Rev Cancer. 2001; 1: 34-45.

25 Gleave M, Hsieh JT, Gao CA, von Eschenbach AC, Chung LW. Acceleration of human priostate cancer growth in vivo by factors produced by prostate and bone fibroblasts. Cancer Res 1991; 51 : 3753-61. 